\title{
TỔNG QUAN HOẠT TÍNH KHÁNG KHUẨN CỦA VẬT LIỆ NANO TRONG CÁC SẢN PHẨM TIÊU DÙNG VÀ THỬC PHẨM, VÀ TìnH HİNH ÚNG DỤNG VẬT LIỆU NANO Ở VIẸT NAM
}

\author{
NGUYẼ̃N HÀ DIÊUU TRANG \\ Viện Công nghệ Sinh học \& Thưc phẩm, Trường Đại học Công nghiệp Thành phố Hồ Chi Minh \\ nguyenhadieutrang@iuh.edu.vn
}

Tóm tắt. Trong những năm gần đây, ứng dụng của vật liệu nano gia tăng trong lĩnh vực khoa học nông nghiệp và thực phẩm. Ngày càng có nhiều ứng dụng của vật liệu nano trong các lĩnh vực khác nhau, và điều này có thể gây ra sự phơi nhiễm của con người và gây ô nhiễm môi trường. Bài báo này nhằm tổng quan các vật liệu nano mới và ứng dụng của chúng trong ngành tiêu dùng và công nghệ thực phẩm. Mục tiêu của bài viết này bao gồm 1) tổng quan các sản phẩm tiêu dùng và thực phẩm có trên thị trường chứa vật liệu nano, đặc biệt là các vật liệu nano vô cơ (vàng, bạc, kẽm oxít, và graphene); 2) các cơ chế kháng khuẩn của vật liệu nano vô cơ; 3) tình hình ứng dụng của vật liệu nano tại Việt Nam. Nhiều kết quả nghiên cứu chứng minh rằng vật liệu nano tương thích sinh học và có tiềm năng được sử dụng trong khoa học nông nghiệp và thực phẩm. Điều này cho thấy cần nhiều nghiên cứu hơn để khai thác các ứng dụng tiềm năng của nó. Dữ liệu cũng cho thấy các vật liệu nano vô cơ có thể được sử dụng như một chất để ức chế sự phát triển của vi khuẩn gây bệnh trong thực phẩm. Cần nhiều nghiên cứu hơn để làm sáng tỏ các cơ chế của kháng khuẩn và độc tính của chúng lên tế bào/mô người để mở đường cho vật liệu nano được ứng dụng nhiều và an toàn hơn cho người tiêu dùng.

Từ khóa: Vật liệu nano, thực phẩm, bạc nano, graphene

\section{ANTIBACTERIAL PROPERTIES OF ENGINEERD NANOPARTICLES AND THEIR APPLICATIONS IN CONSUMER AND FOOD PRODUCTS: A REVIEW AND CURRENT APPLICATIONS OF NANOMATERIALS IN VIETNAM}

\begin{abstract}
There has been increasing application of novel nanomaterials in recent years in various areas, which may cause human exposure and environmental pollution. This review aimed to systematically summarize the use of novel nanomaterials in consumer and food products based on their antibacterial properties. The objectives of this work were to: 1) summarize currently available consumer and food products that contain engineered nanoparticles, 2) study mechanisms of the antibacterial property of engineered nanoparticles, 3) review current applications of engineered nanomaterials in Vietnam. The results demonstrate that many nanoparticles are biocompatible and has a potential to be used in agriculture and food science, indicating that more studies are needed to exploit its potential applications. The summative data also show that nanomaterials can be used as an antimicrobial agent to inhibit the growth of pathogens. More effort is required to further elucidate the antimicrobial mechanism and investigate the cytotoxicity of nanomaterials on human health at hierarchical levels from cellular to the whole organism.
\end{abstract}

Keywords: nanomaterials, food, silver nanoparticles, graphene

\section{GIÓ́I THIỆU}

Vật liệu nano (VLNN) có những đặc tính riêng biệt mà các vật liệu kích thước micro không có, do đó VLNN đã và đang được sử dụng trong nhiềusản phẩm tiêu dùng và ứng dụng trong sản xuất thực phẩm và đóng gói bao bì. Theo thống kê vào năm 2016 của Woodrow Wilson Inventory, một số lượng lớn các VLNN đã được sử dụng trong thuốc, thực phẩm, bao bì, thực phẩm chức năng, thuốc không cần kê đơn, và các sản phẩm mỹ phẩm, kem đánh răng đến sơn, và quần áo (áo thun và vớ) [1]. Có khoản 1814 sản phẩm tiêu dùng có chứa VLNN và số lượng sản phầm đã tăng đều trong vòng 5 năm qua. Có 118 sản phẩm trong danh mục thực phẩm và thức uống (chiếm khoảng 6.5\%) trong khi đó trong danh mục sức khỏe chiếm nhiều sản phẩm nhất (908 sản phẩm, tương đương $50 \%$ tống số). Nano bạc là vật liệu được tìm thấy nhiều nhất trong danh mục thực phẩm (35.5\%) và thường được nhấn mạnh về tính diệt khuẩn của nó. Danh sách các sản phẩm 
tiêu dùng có chứa VLNN được lấy từ dữ liệu databases (Nanodatabase, Nanowek, Nanotechproject.org), tài liệu tham khảo, và internet, được thể hiện ở Bảng 1.

VLNN chủ yếu tìm thấy có trong thực phẩm chức năng, bao bì, và phụ gia thực phẩm. Bên cạnh các VLNN vô cơ (bạc, vàng, kẽm oxít, carbon, vân vân), VLNN hữu cơ được sử dụng trong hầu hết trong thực phẩm chức năng ở dạng mixen hoặc dạng viên bao nano. Những vật liệu mang này thường chứa vitamin, hoặc các hợp chất sinh học. Trong thực phẩm, có ba loại polymer có thể sử dụng, bao gồm nano có nguồn gốc chất béo, nano có nguồn gốc từ chất đạm, và nano có nguồn gốc chất bột. Trong số đó, nano có nguồn gốc chất béo hay được sử dụng nhất do nguồn gốc tự nhiên của nó, khả năng chứa được các hợp chất có độ hòa tan khác nhau. Bảng 1 liệt kê các tinh bột là nguyên liệu hay được sử dụng nhiều nhất làm chất vận chuyển trong thực phẩm.

VLNN được sử dụng trong bao bì thường chứa bạc và đất sét. Tương tự như trong thực phẩm chức năng, nano bạc được dùng chính là chất diệt khuẩn trong bao bì, hộp đựng thực phẩm, và vật dụng nhà bếp. Hiện nay, chưa có bạc bỏ trực tiếp vào thực phẩm, tuy nhiên nano vàng lại được bỏ vào trong một sản phẩm rượu tại Đài Loan [1]. Điều này dễ hiểu vì vàng đã được sử dụng hàng ngàn năm trước trong lịch sử. Titanium dioxide $\left(\mathrm{TiO}_{2}\right)$ thường được sử dụng làm sắc tố trong các sản phẩm bao gồm thực phẩm và mỹ phẩm vì màu trắng sáng của nó. Đất sét nano được sử dụng nhiều nhất trong việc sản xuất vật liệu bao bì, đặc biệt trong việc làm chai nhựa/thủy tinh để nâng cao sức bền và giảm độ bay hơi hương của vật liệu.

Bảng 1. Các sản phẩm thực phẩm hoặc liên quan đến thực phẩm có chứa VLNN trên thế giới

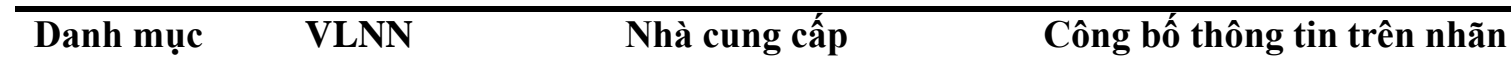

Thực phẩm bổ sung

\begin{tabular}{|c|c|c|}
\hline \multirow[t]{10}{*}{ Bạc nano } & $\begin{array}{l}\text { Natural-Immunogenics } \\
\text { Corp }\end{array}$ & Hệ keo bạc có nồng độ 10-50ppm \\
\hline & Nature City & $\begin{array}{l}\text { Có khả năng chống vi khuẩn, vi rút, } \\
\text { không độc hại, và phi dược phẩm }\end{array}$ \\
\hline & Activz & $\begin{array}{l}\text { Hỗ trợ hệ thống làm lành tự nhiên } \\
\text { của cơ thể }\end{array}$ \\
\hline & Fair vital & $\begin{array}{l}\text { Nồng độ } 500 \text { ppm, tác dụng chống } \\
\text { vi khuẩn }\end{array}$ \\
\hline & American Biotech Labs & $\begin{array}{l}\text { Nồng độ } 10 \text { ppm, giúp nâng cao hệ } \\
\text { thống miễn dịch }\end{array}$ \\
\hline & Silver Support & Nâng cao hệ thống miễn dịch \\
\hline & $\begin{array}{l}\text { Silvix3-Natural Care } \\
\text { Products }\end{array}$ & $\begin{array}{l}\text { Nồng độ } 10 \text { ppm, giúp nâng cao hệ } \\
\text { thống phòng thủ miễn dịch }\end{array}$ \\
\hline & $\begin{array}{l}\text { Sovereign Silver Nano } \\
\text { Hydrosol }\end{array}$ & $\begin{array}{l}\text { Nồng độ } 10 \text { ppm, an toàn hỗ trợ hệ } \\
\text { thống miễn dịch }\end{array}$ \\
\hline & $\begin{array}{l}\text { Skybright Natural } \\
\text { Health }\end{array}$ & $\begin{array}{l}\text { Nồng độ } 6-8 \text { ppm, hỗ trợ hệ thống } \\
\text { miê̂n dịch và khả năng tự làm lành } \\
\text { tự nhiên }\end{array}$ \\
\hline & $\begin{array}{l}\text { MesoSilver-Purest } \\
\text { Colloids Inc. }\end{array}$ & $\begin{array}{l}\text { Kích thước nhỏ hơn hay bằng } 0,65 \\
\text { nm bán kính, nâng cao hệ thống } \\
\text { miễn dịch }\end{array}$ \\
\hline
\end{tabular}


ASAP Double strengthAmerican Biotech Labs

SilverBiotics- American Biotech Labs

MaatShop

Allan Sutton
Skybright Natural
Health
Galaxia Nano
Technology Limited
NanoSil
Greenwood Consumer
Products

Nano-Sized Self- NutraLease Ltd. assembled Liquid Structures

\begin{tabular}{|c|c|}
\hline $\begin{array}{l}\text { Nanocarrier/ingre } \\
\text { dients }\end{array}$ & Nanotrim $^{\mathrm{TM}}$ \\
\hline $\begin{array}{l}\text { Nanocarrier/ingre } \\
\text { dients }\end{array}$ & Fohow \\
\hline $\begin{array}{l}\text { Nano } \\
\text { encapsulation }\end{array}$ & NanoSlim \\
\hline Nanopowder & $\begin{array}{l}\text { Nanoceuticals } \\
\text { Artichoke Nanoclusters- } \\
\text { RBC Life Sciences } ® \text {, } \\
\text { Inc. }\end{array}$ \\
\hline Nanopowder & $\begin{array}{l}\text { Nanoceuticals } \\
\text { Spirulina Nanoclusters- } \\
\text { RBC Life Sciences } ® \text {, } \\
\text { Inc }\end{array}$ \\
\hline $\begin{array}{l}\text { Nano } \\
\text { encapsulation }\end{array}$ & $\begin{array}{l}\text { Inovate Health Sciences } \\
\text { Research, Inc. }\end{array}$ \\
\hline
\end{tabular}

Diatomaceous Bio-Sim-Nano Health earth
Hỗ trợ hệ thống miễn dịch

Hỗ trợ hệ thống miễn dịch

Hỗ trợ hệ thống miễn dịch

Giúp hỗ trợ mắt, mũi, miệng, họng, và phổi

Hỗ trợ loại bỏ vi khuẩn

Bảo vệ và chống vi sinh vật

Dùng cho cholesterol cao, tiểu đường, gút, táo bón, giảm cân, giữ sắc đẹp và các tác dụng khác

Hỗ trợ hệ thống miễn dịch

Vận chuyển các chất như thuốc hay dược phẩm

Tăng sức khỏe tế bào và giúp đốt chất béo tạo năng lượng

Sản phẩm chăm sóc sức khỏe tự nhiên

Giúp giảm cân nhanh hơn

Giảm lực căng bề mặt của thực phẩm, và của thực phẩm bổ sung, để tăng độ dính ướt và độ hấp thu chất dinh dưỡng

Giảm lực căng bề mặt của thực phẩm, và của thực phẩm bổ sung, để tăng độ dính ướt và độ hấp thu chất dinh dưỡng

Tăng độ hấp thu các chất, giúp các VLNN có khả năng thẩm thấu vào cơ thể

Tăng cường hệ thống miễn dịch, chống nấm Candida, và giải độc 


\begin{tabular}{|c|c|c|c|}
\hline Silicon & $\begin{array}{l}\text { Nanosiliceo Kapseln- } \\
\text { Neosino }\end{array}$ & Không có thông tin & \\
\hline $\mathrm{Au} N \mathrm{NP}$ & $\begin{array}{l}\text { Utopia Silver } \\
\text { Supplements Colloidal } \\
\text { Gold } 8\end{array}$ & Không có thông tin & {$[1]$} \\
\hline $\begin{array}{l}\text { Au NP }(0.65 \mathrm{~nm} \text { in } \\
\text { diameter })\end{array}$ & $\begin{array}{l}\text { Mesogold - Colloids for } \\
\text { Life LLC }\end{array}$ & Tăng chức năng não và nhận thức & {$[2]$} \\
\hline Au NP & $\begin{array}{l}\text { Colloidial Gold- } \\
\text { MaatShop }\end{array}$ & $\begin{array}{l}\text { Thông các tắc nghẽn trong cơ thể } \\
\text { và do đó kéo dài tuổi thọ }\end{array}$ & {$[3]$} \\
\hline Zinc & $\begin{array}{l}\text { MesoZinc-Purest } \\
\text { Colloids Inc. }\end{array}$ & Giúp da dẻ khỏe mạnh, tái tạo sụn & {$[4]$} \\
\hline Copper & $\begin{array}{l}\text { MesoCopper } \\
\text { Purest Colloids Inc. }\end{array}$ & $\begin{array}{l}\text { Thúc đẩy quá trình giúp da khỏe } \\
\text { mạnh, tái tạo sụn và gân }\end{array}$ & {$[5]$} \\
\hline Iridium & $\begin{array}{l}\text { Meso Iridium } \\
\text { Purest Colloids Inc. }\end{array}$ & $\begin{array}{l}\text { Thúc đẩy quá trình trao đổi chất của } \\
\text { tế bào được cải thiện }\end{array}$ & {$[6]$} \\
\hline Platinum (10 ppb) & $\begin{array}{l}\text { MesoPlatninum } \\
\text { Purest Colloids Inc. }\end{array}$ & Tăng độ tập trung trí não & [7] \\
\hline $\begin{array}{l}\text { Platinum, gold } \\
\text { and silver }\end{array}$ & $\begin{array}{l}\text { Colloidial Golden } \\
\text { Platinum-MaatShop }\end{array}$ & $\begin{array}{l}\text { Tối ưu hóa chức năng DNA và bảo } \\
\text { vệ cơ thể chống lại bệnh tật }\end{array}$ & {$[8]$} \\
\hline Palladium & $\begin{array}{l}\text { Meso Palladium-Purest } \\
\text { Colloids Inc. }\end{array}$ & $\begin{array}{l}\text { Tăng tối đa diện tích bề mặt của vật } \\
\text { liệu }\end{array}$ & [9] \\
\hline Micelle & Nutrition Centre Ltd & $\begin{array}{l}\text { Mô phỏng cách tiêu hóa chất béo } \\
\text { của vi sinh vật ở đường ruột, tăng } \\
\text { cường khả năng hấp thụ chất dinh } \\
\text { dưỡng lên } 300 \%\end{array}$ & [10] \\
\hline $\begin{array}{l}\text { A micelle, } 30 \mathrm{~nm} \\
\text { in diameter }\end{array}$ & CoQ Softgels -Solgar & $\begin{array}{l}\text { Chuyển hóa chất dinh dưỡng thành } \\
\text { dạng tan trong nước, do đó tăng độ } \\
\text { hấp thu lên nhiều lần }\end{array}$ & [11] \\
\hline $\begin{array}{l}\text { Nano- } \\
\text { encapsulation }\end{array}$ & $\begin{array}{l}\text { Muscletech sports } \\
\text { nutrition supplements }\end{array}$ & $\begin{array}{l}\text { Vận chuyển nhanh các phức chất } \\
\text { vitamin vào trong cơ thể }\end{array}$ & [12] \\
\hline $\begin{array}{l}\text { Lyposomal Nano- } \\
\text { spheres }\end{array}$ & $\begin{array}{l}\text { Vitamin C- } \\
\text { LivOn Labs }\end{array}$ & $\begin{array}{l}\text { Bảo bọc vitamin } \mathrm{C} \text { để vitamin có } \\
\text { thể nhẹ nhàng vượt qua thành ruột } \\
\text { và đi vào trong máu }\end{array}$ & [13] \\
\hline $\begin{array}{l}\text { Micelle } \\
30 \mathrm{~nm} \text { diameter }\end{array}$ & Aquanova & $\begin{array}{l}\text { Tăng độ hấp thu và tăng khả năng } \\
\text { thấm thấu các hoạt chất vào ruột và } \\
\text { da }\end{array}$ & [14] \\
\hline
\end{tabular}




\begin{tabular}{|c|c|c|}
\hline $\begin{array}{l}\text { Nano } \\
\text { encapsulation } \\
\text { natural lipids }\end{array}$ & $\begin{array}{l}\text { NanoResveratrol }^{\mathrm{TM}} \\
\text { Life Enhancement }\end{array}$ & $\begin{array}{l}\text { Làm chất mang gúp chất có hoạt } \\
\text { tính vượt qua các kẽ nhỏ trên thành } \\
\text { tế bào và có thể đi vào trong tế bào }\end{array}$ \\
\hline Unknown & $\begin{array}{l}\text { Life Enhancement } \\
\text { (discontinued) }\end{array}$ & $\begin{array}{l}\text { Nuôi dưỡng và bảo vệ tế bào, mô } \\
\text { và các cơ quan, chống tác nhân lão } \\
\text { hóa }\end{array}$ \\
\hline Curcuminoids & $\begin{array}{l}\text { Life Enhancement } \\
\text { (discontinued) }\end{array}$ & $\begin{array}{l}\text { Chỉ cần dùng một lượng nhỏ nghệ } \\
\text { là đủ đạt mức độ cấn thiêt trong } \\
\text { máu }\end{array}$ \\
\hline $\begin{array}{l}\text { Nanoparticulated } \\
\text { aminos }\end{array}$ & $\begin{array}{l}\text { Alpha Amino Prototype } \\
\text { MuscleTech }\end{array}$ & Giúp cơ bắp săn chắc \\
\hline $\begin{array}{l}\text { Nanocarrier } \\
\text { (mineral clusters) }\end{array}$ & $\begin{array}{l}\text { RBC Life Sciences } ® \text {, } \\
\text { Inc. }\end{array}$ & $\begin{array}{l}\text { Làm ướt tế bào và giúp thể hiện } \\
\text { nhiều chức năng sinh tồn một cách } \\
\text { hiệu quả }\end{array}$ \\
\hline Silica & $\begin{array}{l}\text { MesoSilica } \\
\text { Colloids - Purest } \\
\text { Inc. }\end{array}$ & $\begin{array}{l}\text { Giúp da khỏe mạnh và tái tạo } \\
\text { collagen giúp cho sự đàn hồi da. }\end{array}$ \\
\hline $\begin{array}{l}\text { Silicate mineral } \\
\text { (300 } \mathrm{mg} / \text { capsule })\end{array}$ & $\begin{array}{l}\text { Microhydrin }{ }^{\circledR}-\mathrm{RBC} \\
\text { Life Sciences } ®, \text { Inc. }\end{array}$ & $\begin{array}{l}\text { Cung cấp các vật liệu để tạo năng } \\
\text { lượng, nâng cao sức bền bì và tăng } \\
\text { sự hồi phục }\end{array}$ \\
\hline Calcium & $\begin{array}{l}\text { Good State - Liquid } \\
\text { Ionic Minerals Calcium }\end{array}$ & $\begin{array}{l}\text { Có kích thước rất nhỏ, đường kính } \\
\text { khoảng } 0,1 \text { nm, giúp xương và răng } \\
\text { khỏe, và duy trì răng lợi khỏe mạnh }\end{array}$ \\
\hline $\begin{array}{l}\text { Calcium and } \\
\text { Magnesium }\end{array}$ & Good state & $\begin{array}{l}\text { Giảm huyết áp, và có thể giúp giảm } \\
\text { mật độ xương liên quan đến xương } \\
\text { giòn, giữ da khỏe mạnh }\end{array}$ \\
\hline Calcium & Mag-I-Cal.com & $\begin{array}{l}\text { Hấp thu nano canxi/magie cao hơn } \\
\text { so với các sản phẩm khác }\end{array}$ \\
\hline $\begin{array}{l}\text { CoQ10 and } B- \\
\text { Cyclodextrin }\end{array}$ & Genceutic Naturals & $\begin{array}{l}\text { Ổn định hơn, có thể bảo vệ khỏi } \\
\text { ánh sáng và nhiệt độ }\end{array}$ \\
\hline Zeolite crystals & $\begin{array}{l}\text { Vitality Products Co. } \\
\text { Inc. }\end{array}$ & $\begin{array}{l}\text { Hỗ trợ hệ thống miễn dịch khỏe } \\
\text { mạnh, giúp loại bỏ kim loại nặng, } \\
\text { độc tố và các chất khác ra khỏi cơ } \\
\text { thể }\end{array}$ \\
\hline
\end{tabular}

Hộp đựng thức ăn

$\begin{array}{ll}\text { Ag NP } & \text { Kinetic Go Green } \\ \text { Ag NP } & \begin{array}{l}\text { Basic Nanosilver Oso } \\ \text { Fresh }\end{array}\end{array}$

Giữ cho thực phẩm tươi hơn dài gấp 3 lần so với túi đựng plastic thông thường

Fresh 


\begin{tabular}{|c|c|c|c|c|}
\hline & $\mathrm{Ag} \mathrm{NP}$ & $\begin{array}{l}\text { FresherLonger }{ }^{\mathrm{TM}} \\
\text { Sharper Image }{ }^{\circledR}\end{array}$ & Chống vi khuẩn & [29] \\
\hline & Ag NP & $\begin{array}{l}\text { Fresh Containers }{ }^{\mathrm{TM}} \\
\text { Always Fresh }\end{array}$ & Loại bỏ các khí gây hại & {$[30]$} \\
\hline & $\mathrm{Ag}$ NP & A-DO Global & Chống vi khuẩn ở nồng độ 20 ppm & {$[31]$} \\
\hline & $\mathrm{Ag} \mathrm{NP}$ & $\begin{array}{l}\text { Quan Zhou Hu Zheng } \\
\text { Nano Technology Co., } \\
\text { Ltd }\end{array}$ & Chống vi sinh vật & {$[32]$} \\
\hline & Đất sét (clay) & $\begin{array}{l}\text { Top Nano Technology } \\
\text { Co., Ltd. }\end{array}$ & $\begin{array}{l}\text { Giảm độ cay, mang lại hương thơm } \\
\text { hơn cho rượu mạch nha }\end{array}$ & [33] \\
\hline Lớp phủ ngoài & Nano phim & Constantia Multifilm & $\begin{array}{l}\text { Cản được oxygen tốt hơn vật liệu } \\
\text { PET (Polyethylene terephthalate) } \\
\text { và PVC (Polyvinyl chloride) nhưng } \\
\text { nhẹ và giá cả rẻ hơn }\end{array}$ & {$[34]$} \\
\hline $\begin{array}{l}\text { Lớp phủ thực } \\
\text { phẩm }\end{array}$ & $\begin{array}{l}\text { Các hạt VLNN } \\
\text { phân bố đơn lẻ }\end{array}$ & $\begin{array}{l}\text { TopScreen DS13 - } \\
\text { Topchim }\end{array}$ & $\begin{array}{l}\text { Có nguồn gốc sáp nước và sinh } \\
\text { học, làm màng bọc có thể chịu } \\
\text { nhiệt độ cao hơn và ít dính hơn }\end{array}$ & {$[35]$} \\
\hline $\begin{array}{l}\text { Túi đựng sữa } \\
\text { mẹ }\end{array}$ & $\mathrm{Ag} \mathrm{NP}$ & Jaco & Không có thông tin & {$[36]$} \\
\hline $\begin{array}{l}\text { Bình đựng } \\
\text { nước }\end{array}$ & $\mathrm{Ag} \mathrm{NP}$ & $\begin{array}{l}\text { Chronic Nano } \\
\text { Technology }\end{array}$ & $\begin{array}{l}\text { Loại bỏ các gốc tự do, tăng cường } \\
\text { hệ miê̂n dịch }\end{array}$ & {$[37]$} \\
\hline $\begin{array}{l}\text { Bình đựng } \\
\text { nước }\end{array}$ & $\mathrm{Ag} \mathrm{NP}$ & A-DO Global & Chống lại vi khuẩn & {$[38]$} \\
\hline Tô đựng salad & $\mathrm{Ag} \mathrm{NP}$ & Changmin Chemicals & Không có thông tin & [39] \\
\hline Chảo & Carbon & Melitta & $\begin{array}{l}\text { Làm nóng thực phẩm nhanh chóng } \\
\text { (nhanh hơn } 30 \% \text { thời gian nâu } \\
\text { nướng) }\end{array}$ & {$[40]$} \\
\hline Màng lọc & Nano alumina & $\begin{array}{l}\text { NanoCeram-PAC } \\
\text { Argonide }\end{array}$ & Có khả năng bắt các hạt rất nhỏ & {$[41]$} \\
\hline Lọc nước & Ceramic & Eurodia & $\begin{array}{l}\text { Tách nước cùng lúc với tách các hạt } \\
\text { ion }\end{array}$ & {$[42]$} \\
\hline $\begin{array}{l}\text { Màng bọc } \\
\text { plastic }\end{array}$ & $\mathrm{ZnO}$ & $\begin{array}{l}\text { SongSing Nano } \\
\text { Technology Co., Ltd. }\end{array}$ & $\begin{array}{l}\text { Chống tia UV, phản xạ tia hồng } \\
\text { ngoại, tiệt trùng và chống mốc }\end{array}$ & {$[43]$} \\
\hline $\begin{array}{l}\text { Chai nhựa } \\
\text { đựng bia }\end{array}$ & Đất sét (clay) & Voridian & $\begin{array}{l}\text { Giữ bia tươi hơn và kéo dài thời } \\
\text { gian bảo quản }\end{array}$ & {$[44]$} \\
\hline Chai bia & Đất sét (clay) & Honeywell & $\begin{array}{l}\text { Cản được oxy xâm nhập trong thời } \\
\text { gian dài }\end{array}$ & {$[45]$} \\
\hline
\end{tabular}


Thực phẩm

\begin{tabular}{|c|c|c|c|c|}
\hline Rượu & $\mathrm{Au} \mathrm{NP}$ & Taiwanese YuShanJin & $\begin{array}{l}\text { Gia tăng giá trị cảm quan (giảm } \\
\text { cảm giác cháy miệng khi uống } \\
\text { rượu) }\end{array}$ & [46] \\
\hline $\begin{array}{l}\text { Sy-rô } \\
\text { chocolate }\end{array}$ & Titanium dioxide & Albertsons & Nồng độ $0,0025 \mu \mathrm{g}$ Ti/mg & [47] \\
\hline $\begin{array}{l}\text { Sy-rô } \\
\text { chocolate }\end{array}$ & Titanium dioxide & The Hershey Company & Nồng độ $0,0026 \mu \mathrm{g}$ Ti/mg & [48] \\
\hline $\begin{array}{l}\text { Kẹo bánh } \\
\text { (chocolae, kẹo } \\
\text { gum, bánh qui) }\end{array}$ & $\begin{array}{l}\text { Titanium dioxide } \\
\text { oxide }\end{array}$ & M\&M Company & Có kích thước nhỏ hơn $450 \mathrm{~nm}$ & \\
\hline Dầu hoa cải & $\begin{array}{l}\text { Nanodrops } \\
\text { (mixen) }\end{array}$ & Shemen Industries & $\begin{array}{l}\text { Ngăn chặn cholesterol từ trong hệ } \\
\text { tiêu hóa đi ra hệ máu }\end{array}$ & [49] \\
\hline Nước khoáng & $\operatorname{Ag}$ NP $(100 \mathrm{pm})$ & La Posta del Aguila & $\begin{array}{l}\text { Dành cho bà mẹ và trẻ em trong } \\
\text { giai đoạn mang thai. Chống vi sinh } \\
\text { vật }\end{array}$ & [50] \\
\hline Chocolate & Nanocarrier & $\begin{array}{l}\text { Nanoceuticals }{ }^{\mathrm{TM}} \text { Slim } \\
\text { Shake Chocolate }\end{array}$ & $\begin{array}{l}\text { Tăng cường hương vị và lợi ích của } \\
\text { thực phẩm }\end{array}$ & [51] \\
\hline Trà & $\begin{array}{l}\text { Selenium } \\
\text { nanoparticles }\end{array}$ & $\begin{array}{l}\text { Shenzhen Become } \\
\text { Industry \& Trade Co., } \\
\text { Ltd. }\end{array}$ & Tiêu diệt vi-rút & [52] \\
\hline Keo dán & $\begin{array}{l}\text { Biopolymer (tinh } \\
\text { bột) }\end{array}$ & Ecosynthetix & $\begin{array}{l}\text { Làm khô nhanh so với hơn tinh bột } \\
\text { truyền thống }\end{array}$ & [53] \\
\hline Bột đánh răng & $\begin{array}{l}\text { Nanopowder } \\
\text { (silicon) }\end{array}$ & $\begin{array}{l}\text { RBC Life Sciences } ® \text {, } \\
\text { Inc. }\end{array}$ & $\begin{array}{l}\text { Giảm sức căng bề mặt của thực } \\
\text { phẩm và làm chất bồ sung để tăng } \\
\text { độ ẩm và hấp thụ chất dinh dưỡng }\end{array}$ & [54] \\
\hline \multicolumn{5}{|l|}{ Dụng cụ nhà bếp } \\
\hline Thớt cắt & Ag NP & Husk's Kitchen & $\begin{array}{l}\text { Có thể phân hủy sinh học và chống } \\
\text { vi khuấn }\end{array}$ & [55] \\
\hline Thớt cắt & Ag NP & A-DO Global & Chống vi khuẩn & [56] \\
\hline Thớt cắt & Ag NP & $\begin{array}{l}\text { Pro-Idee GmbH \& Co. } \\
\text { KG }\end{array}$ & $\begin{array}{l}\text { Chống lại vi khuẩn và tiêu diệt trên } \\
99.9 \% \text { vi trùng }\end{array}$ & [57] \\
\hline \multirow[t]{3}{*}{ Chảo rán } & $\mathrm{Ag}$ NP & Concord Cookware & Phủ lớp nano bạc trong và ngoài & [58] \\
\hline & Ag NP & Korea King & Tiệt trùng và chống vi khuẩn & [59] \\
\hline & $\mathrm{Ag} \mathrm{NP}$ & Amoré TM Kitchenware & $\begin{array}{l}\text { Ngăn chặn sự phát triển của vi sinh } \\
\text { vật, mốc, vâ nấm mốc }\end{array}$ & [60] \\
\hline
\end{tabular}




\begin{tabular}{|c|c|c|c|c|}
\hline Lọc nước & Ag NP & Katadyn Asia Inc. & $\begin{array}{l}\text { Giảm sự phát triển của vi khuẩn ở } \\
\text { trong ông ceramic, diệt khuâ̂n liên } \\
\text { tục }\end{array}$ & {$[61]$} \\
\hline Bếp nấu & $\begin{array}{l}\text { Nano-Carbon } \\
\text { Fiber }\end{array}$ & Sunpentown & $\begin{array}{l}\text { Làm nóng nhanh, tiết kiệm thời } \\
\text { gian nấu và năng lượng. }\end{array}$ & {$[62]$} \\
\hline Bình trà & Metals & $\begin{array}{l}\text { Top Nano Technology } \\
\text { Co., Ltd. }\end{array}$ & $\begin{array}{l}\text { Giải phóng hương vị trà trong vòng } \\
30 \text { giây }\end{array}$ & {$[63]$} \\
\hline \multirow{2}{*}{$\begin{array}{l}\text { Đồ đựng thủy } \\
\text { tinh }\end{array}$} & Nanofilms & Nanofilm & Lớp phủ không dính cho thủy tinh & [64] \\
\hline & Ag NP & $\begin{array}{l}\text { Westfalia } \\
\text { Wergzeugcompany } \\
\text { GmbH \& CO KG }\end{array}$ & Chống vi khuẩn và vi trùng & {$[65]$} \\
\hline $\begin{array}{l}\text { Dụng cụ nấu } \\
\text { nướng }\end{array}$ & Glaze & Ceramcor LLC & Giữ nhiệt và phân bố nhiệt tốt & \\
\hline Chảo & Nano-ceramic & Bialetti & $\begin{array}{l}\text { Lớp phủ làm từ Titan và các hạt vi } \\
\text { silicat lơ lửng }\end{array}$ & {$[66]$} \\
\hline $\begin{array}{l}\text { Dụng cụ nhà } \\
\text { bếp }\end{array}$ & Ag NP & $\begin{array}{l}\text { Nano Care Technology, } \\
\text { Ltd. }\end{array}$ & $\begin{array}{l}\text { Tiêu diệt các vi khuẩn và vi sinh vật } \\
\text { mảng bám trong vòng } 10 \text { phút và } \\
\text { có tác dụng trong thời gian dài }\end{array}$ & {$[67]$} \\
\hline $\begin{array}{l}\text { Máy pha cà } \\
\text { phê }\end{array}$ & Ag NP & Saeco United States Inc. & $\begin{array}{l}\text { Đảm bảo các vật dụng chứa sũ̃a đều } \\
\text { sạch } 100 \%\end{array}$ & {$[68]$} \\
\hline $\begin{array}{l}\text { Máy rửa rau và } \\
\text { trái cây }\end{array}$ & Ag NP & $\begin{array}{l}\text { Jiekang Technology } \\
\text { (Shen Zhen) Co., Ltd. }\end{array}$ & Giảm sự phát triển của vi khuẩn & [69] \\
\hline $\begin{array}{l}\text { Máy rửa rau và } \\
\text { trái cây }\end{array}$ & Ag NP & 3EVER Co.,Ltd & $\begin{array}{l}\text { Tiêu diệt vi khuẩn Bacillus, } \\
\text { Salmonella and E. coli O-157 }\end{array}$ & [70] \\
\hline Dầu nấu ăn & Ag NP & $\begin{array}{l}\text { SongSing Nano } \\
\text { Technology Co., Ltd. }\end{array}$ & $\begin{array}{l}\text { Tiêu diệt vi khuẩn Staphyloccus. } K \text {. } \\
\text { pneumoniae, E. coli, } P \text {. } \\
\text { aeruginosa, etc. }\end{array}$ & [71] \\
\hline \multicolumn{5}{|l|}{ Đồ dùng trẻ em } \\
\hline Bình sữa & Ag NP & BabyDream & $\begin{array}{l}\text { Gúp bảo vệ em bé có hệ thống miễn } \\
\text { dịch yếu khỏi vi trùng, và nguồn } \\
\text { gây bệnh }\end{array}$ & [72] \\
\hline $\begin{array}{l}\text { Ly tập uống } \\
\text { nước }\end{array}$ & Ag NP & BabyDream & $\begin{array}{l}\text { Gúp bảo vệ em bé có hệ thống miễn } \\
\text { dịch yếu khỏi vi trùng, và nguồn } \\
\text { gây bệnh }\end{array}$ & {$[73]$} \\
\hline Núm ty giả & Ag NP & BabyDream & $\begin{array}{l}\text { Gúp bảo vệ em bé có hệ thống miễn } \\
\text { dịch yếu khỏi vi trùng, và nguồn } \\
\text { gây bệnh }\end{array}$ & [74] \\
\hline
\end{tabular}




\section{THUỘC TÍNH KHÁNG VI SINH VẬT CỦA VLNN VÔ CƠ}

Một số VLNN có tính kháng vi sinh vật như các vi khuẩn gây bệnh cho người. Bảng 2 tóm tắt kết quả của các nghiên cứu gần đây về thuộc tính kháng vi sinh vật của VLNN vô cơ, bao gồm kim loại, oxít kim loại, và vật liệu nguồn gốc carbon, chống lại các vi khuẩn gây bệnh, vi-rút, và ký sinh trùng. Ví dụ, trong các nghiên cứu gần đây đã chỉ ra rằng Selenium nano có khả năng chống lại vi sinh vật Trichophyton rubrum [2], Candida albicans [3], Pseudomonas aeruginosa, and Proteus mirabilis [4].

Bảng 2. Tác dụng chống vi sinh vật của VLNN vô cơ lên các loại vi sinh vật khác nhau

\begin{tabular}{|c|c|c|c|}
\hline Vi sinh vật & VLNN & Tác dụng & $\begin{array}{l}\text { Tài liệu tham } \\
\text { khảo }\end{array}$ \\
\hline & Selenium nano (Se NP) & & \\
\hline \multicolumn{4}{|l|}{ Bacteria and yeasts } \\
\hline Trichophyton rubrum & $\begin{array}{l}\text { Được đệm lên vải bằng } \\
\text { phức hợp PSP-Se NP }\end{array}$ & $\begin{array}{l}\text { Úc chế hơn } 99,7 \% \text { tăng } \\
\text { trưởng trong thời gian thử } \\
\text { nghiệm } 7 \text { ngày }\end{array}$ & {$[2]$} \\
\hline Candida albicans & $\begin{array}{l}\text { Sản xuất ra từ } \\
\text { Lactobacillus species }\end{array}$ & $\begin{array}{l}\text { Tăng cường hoạt tính kháng } \\
\text { nấm chống lại } C \text {. albicans. }\end{array}$ & {$[3]$} \\
\hline Staphylococcus aureus & Kích thước 50-100 nm & $\begin{array}{l}\text { Hoàn toàn ức chế được sự } \\
\text { phát triển khi thực nghiệm } \\
\text { trong ống nghiệm }\end{array}$ & {$[5]$} \\
\hline $\begin{array}{l}\text { S. aureus and Pseudomonas. } \\
\text { aeruginosa }\end{array}$ & Kích thước $50 \mathrm{~nm}$ & $\begin{array}{l}\text { Úc chế sự tăng trưởng của } S \text {. } \\
\text { aureus và } P \text {. aeruginosa } \\
80 \% \text { 90\% sau } 72 \text { giờ trên } \\
\text { khăn giấy }\end{array}$ & [6] \\
\hline $\begin{array}{l}\text { Escherichia coli (MTCC } \\
\text { 433) and Bacillus subtilis } \\
\text { (MTCC 441) }\end{array}$ & Kết hợp giữa $\mathrm{Ag}-\mathrm{Se} \mathrm{NP}$ & $\begin{array}{l}\text { Hiển thị vùng ức chế trong } \\
\text { cả hai trường hợp trên môi } \\
\text { trường thạch }\end{array}$ & [7] \\
\hline $\begin{array}{l}\text { Thirty } \quad \text { strains } \quad \text { of } S . \\
\text { aureus, } P . \quad \text { aeruginosa, } \\
\text { and Proteus mirabilis }\end{array}$ & Kích thước $80-220 \mathrm{~nm}$ & $\begin{array}{l}\text { Úc chế màng sinh học của } S \text {. } \\
\text { aureus, } P \text {. aeruginosa và } P \text {. } \\
\text { mirabilis lần lượt là } 42 \% \text {, } \\
34,3 \% \text { và } 53,4 \%\end{array}$ & {$[4]$} \\
\hline S. aureus & Kích thước 100 nm & $\begin{array}{l}\text { Úc chế sự tăng trưởng của } S \text {. } \\
\text { aureus trong nước dùng sau } \\
3,4 \text { và } 5 \text { giờ ở mức } 7,8,15,5 \\
\text { và } 31 \mu \mathrm{g} / \mathrm{mL}\end{array}$ & {$[8]$} \\
\hline
\end{tabular}

\section{Bạc nano (Ag NP)}

Vi khuẩn và nấm

S. aureus, E. coli, Klebsiella

pneumoniae, B. subtilis,

Enterococcus faecalis,

Hoạt động kháng khuẩn

[9]

$P$. aeruginosa

đáng kể, có thể chống lại tất

cả các vi khuẩn gây bệnh 
S. aureus và Streptococcus mutans, C. albicans

S. aureus, methicillinsensitive $S$. aureus (MSSA), and MRSA

Salmonella Typhi, Staphylococcus epidermidis, S. aureus, $P$. aeruginosa, $P$. vulgaris, E.coli, K. pneumoniae
Vật liệu y tế phủ lớp bạc nano Ag NP

Vật liệu composite kết hợp giữa cellulose nguồn gốc từ vi khuẩn và bạc nano

0,1\% kết hợp bạc nano cho thấy tác dụng diệt khuẩn đối với hai chủng vi khuẩn. Tổ hợp 5\% bạc nano có khả năng diệt nấm

[10]

Kích thước 5-10 nm

Cho thấy cả tác dụng ức chế vi khuẩn và diệt khuẩn

Hệ keo bạc, kích thước 20-45 nm

Nồng độ ức chế vi sinh vật

khoảng $2-4 \mu \mathrm{g} \mathrm{ml}^{-1}$

\section{Vi khuẩn}

MS2 Average $21 \mathrm{~nm}$

Tạo điều kiện cho MS2 lây nhiễm ký chủ $E$. coli trong một giờ trước khi tiếp xúc

\begin{tabular}{|c|c|c|}
\hline \multicolumn{3}{|l|}{ Ký sinh trùng } \\
\hline Hematophagous parasites & $\begin{array}{l}\text { 60-150 nm } \\
\text { Kẽm oxít ( } \mathrm{ZnO} \mathrm{NP})\end{array}$ & {$[15]$} \\
\hline \multicolumn{3}{|l|}{ Ký sinh trùng } \\
\hline Ký sinh trùng hút máu & Kích thước $60-120 \mathrm{~nm}$ & $\begin{array}{l}\text { Tỷ lệ chết là } 100 \% \text { sau } 12 \text { [16] } \\
\text { giờ }\end{array}$ \\
\hline \multicolumn{3}{|l|}{ Bacteriophage } \\
\hline MS2 & $\begin{array}{l}\text { Kích thước trung bình là } \\
39 \mathrm{~nm}\end{array}$ & $\begin{array}{l}\text { Tạo điều kiện cho MS2 lây [14] } \\
\text { nhiê̂m ký chủ } E \text {. coli trong } \\
\text { một giờ trước khi tiếp xúc }\end{array}$ \\
\hline \multicolumn{3}{|c|}{ Vi sinh vật, nấm men, và tảo nấm } \\
\hline Campylobacter jejuni & $\begin{array}{l}\text { Kích thước khoảng 30 } \\
\text { nm }\end{array}$ & $\begin{array}{l}\text { Hạt nano } \mathrm{ZnO} \text { có thể tiêu [17] } \\
\text { diệt được } C \text {. jejuni }\end{array}$ \\
\hline $\begin{array}{l}\text { Botrytis cinerea và } \\
\text { Penicillium expansum }\end{array}$ & $70 \pm 15 \mathrm{~nm}$ & $\begin{array}{l}\text { Ở nồng độ lớn hơn } 3 \mathrm{mM} \text { có } \\
\text { thể ức chế đáng kể sự phát } \\
\text { triển của hai loại vi khuẩn } \\
\text { Botrytis cinerea và } \\
\text { Penicillium expansum }\end{array}$ \\
\hline
\end{tabular}


Salmonella Typhimurium và $\leq 50 \mathrm{~nm}$

S. aureus

S. aureus

E. coli, Bacillus subtilis, và $50-70 \mathrm{~nm}$

S. aureus

S. aureus và biofilm

P.aeruginosa và Aspergillus flavus

Tổng hợp bằng sinh học
kích thước $57-72 \mathrm{~nm}$

S. Typhimurium và $S$. Tẩm trên vật liệu bao bì aureus trong sản phẩm thịt với kích thước $\leq 100 \mathrm{~nm}$ gà ăn liền

Streptococcus mutans và Dạng bột với kích thước Lactobacillus

Salmonella trong sản phẩm Vật liệu PLA phủ 1 lớp trứng lỏng

\section{S. aureus và $B$. subtilis}

Bạc pha cùng $\mathrm{ZnO}$

Vi khuẩn chịu muối và chịu Kích thước $\leq 100$ nm nhiệt độ thấp

Vi khuẩn và nấm gây bệnh

Tổng hợp sinh học, kích

S. aureus và $P$. aeruginosa
$10-30 \mathrm{~nm}$

$\mathrm{ZnO}$ on PVC composite

Sự hiện diện của $\mathrm{ZnO}$ làm giảm vi khuẩn hoạt động trên các mẫu

Vùng ức chế tối đa là Pseudomonas aeruginosa $(22 \pm 1,8 \mathrm{~mm})$ và Aspergillus flavus $(19 \pm 1,0$ $\mathrm{mm}$ ). hạt trung bình khoảng $50 \mathrm{~nm}$

kẽm oxít khoảng 250 $\mathrm{mg}$ thước $40 \mathrm{~nm}$

Giảm số lượng tế bào về 0 trong vòng 8 giờ

Cho thấy tác dụng kháng khuẩn mạnh hơn nhiều đối với vi khuẩn gram dương so với vi khuẩn gram âm

$\mathrm{ZnO}$ được phát hiện là chất độc thứ hai trong số các hạt nano được thử nghiệm $\left(\mathrm{CuO}, \mathrm{NiO}\right.$, and $\left.\mathrm{Sb}_{2} \mathrm{O}_{3}\right)$

Giảm số lượng vi khuẩn nhiễm từ $\log$ bảy xuống 0 trong vòng 10 ngày ở $8^{\circ} \mathrm{C}$.

Thể hiện hoạt tính chống vi khuẩn cao hơn đối với mẫu chứng

Sự kết hợp giữa PLA và kẽm oxít làm giảm hiệu quả mầm bệnh hoặc kìm hãm sự phát triển của chúng

Nồng độ khác nhau của $\mathrm{Ag}$ ảnh hường đến giá trị MIC

Giảm 50\% sự phát triển của Enterobacter sp. Trong khi đó giảm $80 \%$ sự phát triển vi khuẩn kháng muối Marinobacter sp.

Hoạt tính diệt khuẩn được tăng cường hơn khi so sánh với các hạt nano $\mathrm{ZnO}$ tổng hợp bằng hóa học

Kết hợp với tia UV và hạt nano kích thước trung bình khoảng 60 Làm giảm hơn $4 \log$ (tương đương với kháng sinh) so với mẫu chứng chỉ sau 8 giờ.
[19] $\mathrm{nm}$ 
E. coli và Staphylococcus subtilus, Bacillus megaterium, S. aureus, Sarcina lutea, E. coli, $P$. aeruginosa, K. pneumoniae, $P$. vulgaris, $C$. albicans và Aspergillus niger)

C. albicans

$P$. aeruginosa
Tổng hợp sinh học sử dụng chiết xuất lá cây dâm bụt Hibiscus subdariffa, kích thước hạt khoảng 12-46 nm

Kích thước 11,6 nm

Kích thước $20 \pm 3 \mathrm{~nm}$
Có tác dụng hạn chế sự phát triển của vi khuẩn tốt nhưng tác dụng tiêu diệt khuẩn kém đối với tất cả các mầm bệnh được thử nghiệm

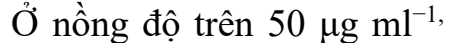
cho thấy hiệu quả diệt khuẩn rất tốt

Khả năng sống của $C$ albicans phụ thuộc vào nồng [33] độ của $\mathrm{ZnO}$ và $\mathrm{MIC}$ là 0,1 $\mathrm{mg} / \mathrm{ml}$

Loại bỏ vi khuẩn trong gan nhưng thay đổi được vi khuẩn trong máu

\section{Graphene (G) và dẫn xuất của nó}

\section{Bacteria}

\begin{tabular}{ll}
\hline E. coli & $\begin{array}{l}\text { Màng membrane } \\
\text { graphene oxít }(\mathrm{GO})\end{array}$
\end{tabular}

E. coli

GO

Khoảng $92 \%$ và $72 \%$ E. coli

[35]

còn lại trên bề mặt membrane sau 1 giờ và 5 giờ xử lý với $\mathrm{GO}$

Vi khuẩn có thể khử graphene oxít thành graphene và tự diệt khuẩn

E. coli, S. Typhimurium, E. faecalis, B. subtilis

$S$. aureus và $E$. coli
Được tổng hợp bởi phương pháp thủy nhiệt

Tác nhân quang nhiệt làm từ $\mathrm{G}$

Vật liệu tổng hợp G dẫn xuất Poly-L-Lysine

Màng nanocompozit graphene (PVK-GO)
Hoạt tính kháng khuẩn chiếm ưu thế so với kháng sinh kanamycin cả hai loại vi khuẩn trong 10 phút

Các chất kháng khuẩn mạnh nhất

Hiệu quả hơn 90\% trong [40] việc ngăn chặn sự xâm nhập 


\begin{tabular}{|c|c|c|c|}
\hline & & $\begin{array}{l}\text { của vi khuẩn so với bề mặt } \\
\text { không sử dụng GO }\end{array}$ & \\
\hline \multirow[t]{2}{*}{ E. coli và $P$. aeruginosa. } & $\begin{array}{l}\text { Vật liệu bạc và GO kết } \\
\text { hợp với nhau }\end{array}$ & $\begin{array}{l}\text { Hoạt tính chống khuẩn tốt } \\
\text { đối với cả hai loại vi khuẩn }\end{array}$ & {$[41]$} \\
\hline & $\begin{array}{l}\text { Ag/G } \\
\text { Hydrogel polymer }\end{array}$ & & [41] \\
\hline$P$. aeruginosa và $S$. aureus & $\begin{array}{l}\text { G nanofilms với độ dài } \\
\text { cạnh khác nhau }\end{array}$ & $\begin{array}{l}\text { Hiệu quả diệt khuẩn khác } \\
\text { nhau đối với hai loại vi } \\
\text { khuẩn gây bệnh }\end{array}$ & {$[42]$} \\
\hline E. coli $\mathrm{O} 157: \mathrm{H} 7$ & $\begin{array}{l}\text { Màng sinh học 3D xốp } \\
\text { kết hợp ống nano carbon }\end{array}$ & $\begin{array}{l}\text { Khả năng cao loại bỏ được } \\
\text { vi khuẩn } E \text {. coli O157: H7 }\end{array}$ & [43] \\
\hline $\begin{array}{l}\text { Methicillin-resistant } S . \\
\text { aureus (MRSA) pathogens }\end{array}$ & $\begin{array}{l}\text { Màng GO liên hợp } \\
\text { peptide }\end{array}$ & $\begin{array}{l}\text { Gần như } 100 \% \text { MRSA có } \\
\text { thể bị loại bỏ và tiêu diệt } \\
\text { khỏi mấu nước }\end{array}$ & [44] \\
\hline $\begin{array}{l}P . \text { syringae và } X \text {. campestris } \\
\text { pv. undulosa) }\end{array}$ & GO & $\begin{array}{l}\text { Giết chết gần } 90 \% \text { vi khuẩn } \\
\text { và ức chế } 80 \% \text { sự nảy mầm } \\
\text { của macroconidia }\end{array}$ & {$[45]$} \\
\hline $\begin{array}{l}\text { Fungal pathogens }(F . \\
\text { graminearum và } \\
\text { oxysporum }\end{array}$ & & & \\
\hline Streptococcus mutans & G nanoplatelets (GNP) & $\begin{array}{l}\text { Tác dụng tiêu diệt các tế bào } \\
S \text {. mutans và phụ thuộc vào } \\
\text { kích thước và độ dày bên } \\
\text { của GNP }\end{array}$ & {$[46]$} \\
\hline $\begin{array}{l}\text { E. coli, S. Typhimurium, B. } \\
\text { subtilis, E. faecalis }\end{array}$ & GO-modified $\mathrm{ZnO} \mathrm{NP}$ & Tính kháng vi sinh vật rất tốt & [47] \\
\hline
\end{tabular}

\section{CƠ CHẾ ĐẬC TÍNH KHÁNG KHUẨN CỦA HẠT NN VÔ CƠ}

Cơ chế đặc tính kháng khuẩn của VLNN vô cơ vẫn chua được hoàn toàn hiểu rõ. Tính kháng khuẩn của hạt $\mathrm{NN}$ là do sự hình thành các gốc oxy phản ứng (ROS), giải phóng các ion kim loại (MMs) độc hại, sự xâm nhập vào tế bào và phá vỡ màng tế bào (Hình 1$)$.

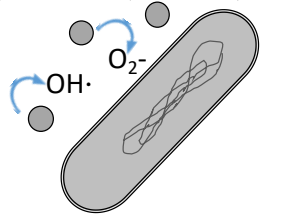

ROS generation

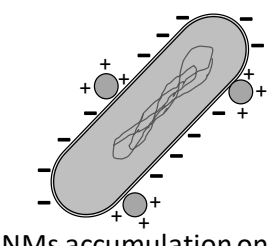

NMs accumulation on membrane surface
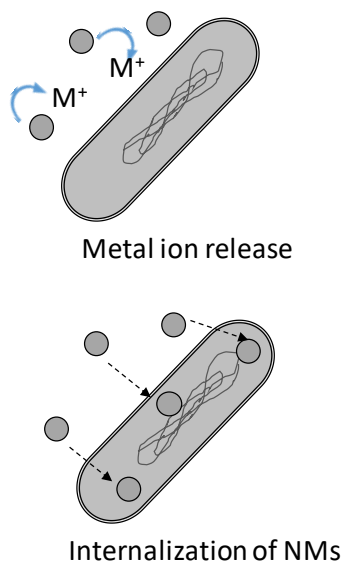

Hình 1. Hình ảnh mô tả cơ chế đặc tính kháng thể của hạt NN kim loại oxít (trích từ tài liệu [48]) 


\subsection{Sự hình thành các ROS}

Trong nhiều nghiên cứu, ROS được xem là tác nhân góp phần phá hủy tế bào [49-55] trong khi đó có một số nghiên cứu lại chỉ ra rằng các ROS trung gian không có vai trò trong đặc tính kháng vi sinh vật của hạt $\mathrm{NN}$ [56] [57], [58]. ROS được tạo ra là do sự tương tác giữa hạt $\mathrm{NN}$ và tế bào tạo ra $\mathrm{ROS}$, không phải là do mỗi hạt NN tự tạo ra một cách tự nhiên [48]. Sự hình thành ROS liên quan đến sự thiếu hụt oxygen, gốc tự do, ion superoxide, và hydrogen peroxide. Sự hình thành các gốc tự do cũng là một cơ chế khá rõ của bạc NN [59]. Khi các hạt nano bám vào tế bào vi khuẩn, những gốc tự do này có thể phá hủy thành tế bào, làm cho màng thủng và từ đó làm dịch bào chảy hết và gây chết tế bào $[60,61]$. Tương tự như kim loại và kim loại oxít, tế bào bị stress là một cơ chế liên quan đến độc tính của các VLNN có gốc carbon [62]. Điều này giải thích tại sao nếu ROS không bị giảm đi hoặc loại bỏ thì các đại phân tử tế bào, chẳng hạn như protein, DNA và lipid có thể đã bị hỏng [63].

\subsection{Cơ chế giải phóng các ion kim loại và độc tính của nó}

Thông thường để kiểm tra giả thuyết về sự giải phóng các ion kim loại của hạt nano, các nghiên cứu thường được sử dụng cách so sánh độc tính của NP kim loại với độc tính của các muối kim loại khác nhau (clorua, nitrat, v.v.). Các ion kim loại này có thể tương tác với các nhóm thiol của nhiều enzyme quan trọng và làm bất hoạt chúng [59]. Sự ức chế enzyme hô hâp bởi các ion bạc có thể dẫn đến việc tạo ra ROS sau đó tấn công chính tế bào. Hơn nữa, khi các tế bào "nuốt" các ion, các ion này sẽ ức chế một số chức năng trong tế bào và gây ra tổn thương các tế bào. Loại độc tính do giải phóng ion kim loại đã được tìm thấy ở $\mathrm{ZnO}$ [64, 65], ở bạc [66, 67], ở $\mathrm{CuO}, \mathrm{NiO}, \mathrm{MgO}, \mathrm{WO}_{3}$ [68], và $\mathrm{CeO}_{2}$ [69-71]. Một nghiên cứu cho thấy cơ chế độc tính này liên quan đến việc giải phóng các ion $\mathrm{Ag}^{+}$. Trong nghiên cứu này, bạc nano và muối bạc nitrat $\mathrm{AgNO}_{3}$ đều được khử ion thông qua nhựa resin trao đổi ion [72]. Tuy nhiên, kết quả cho thấy ion $\mathrm{Ag}^{+}$tự do tồn tại không chỉ trong các dung dịch bac nano mà còn cả trong dung dịch $\mathrm{AgNO}_{3}$. Điều này chứng tỏ rằng cơ chế giải phòng $\mathrm{Ag}^{+}$trong việc giải thích cơ chế độc tính của $\mathrm{Ag} \mathrm{NP}$ vẫn còn nhiều tranh cãi. Trong trường hợp kẽm oxít nano, đã có kết quả nghiên cứu khá mâu thuẫn về mối quan hệ giữa giải phóng ion $\mathrm{Zn}^{+}$và khả năng kháng khuẩn của kẽm oxít nano. Ví dụ, các tế bào hoại tử Cupriavidus khi đã tiếp xúc với $\mathrm{Zn}^{2+}$ sẽ dẫn đến biểu hiện tăng các protein liên quan đến quá trình trao đổi chất, trong khi việc tiếp xúc với kẽm oxít (không phải dạng nano) sẽ dẫn đến biểu hiện tăng protein liên quan đến sinh tổng hợp màng tế bào [73].

\subsection{Các cơ chế khác}

Một cơ chế khác của đặc tính kháng khuẩn của hạt NN là thay đổi cấu trúc trong màng tế bào. Độc tính của nano oxít kim loại được cho là do sự kết dính của hạt nano với màng tế bào, do đó gây ra stress oxy hóa cho tế bào bằng cách thay đổi tính thẩm thấu của màng tế bào, độ nhớt, khả năng trao đổi vận chuyển và cuối cùng dẫn đển tế bào chết $[69,74,75]$. VLNN có thế tương tác với màng tế bào không chỉ thông qua tương tác tĩnh điện mà còn các tương tác có thể khác, bao gồm lực Van der Waals, tương tác kỵ nước và tương tác phối tử - thụ thể. Các loại tương tác hóa lý khác nhau giữa các hat nano và tế bào vi khuẩn có thể giải thích tại sao các hạt nano tích điện âm có thể dễ dàng gắn vào một tế bào Gram âm. Một số nghiên cứu đã xác minh sự phá vỡ màng tế bào bằng oxít kim loại bằng các thí nghiệm proteomics cho thấy sự biến dạng màng tế bào khi tiếp xúc với hạt nano $[64,73,76-78]$ cho thấy rõ rằng sự hiện diện của nano kẽm oxít đã dẫn đến sự phá hủy màng tế bào của $E$. coli. Các hạt nano bạc có khả năng bám vào thành tế bào vi khuẩn và cuối cùng xâm nhập vào nó, hình thành nên các lỗ nhỏ và tích tụ trên bề mặt tế bào [67]. Zhang và cộng sự (2007) cho thấy rõ rằng sự hiện diện của nano kẽm oxít đã dẫn đến sự phá hủy màng tế bào của E. coli [79]. Trong một số nghiên cứu về độc tính của vật liệu họ graphene [50,80], kết quả chỉ ra rằng vì graphene sở hữu các cạnh sắc nét và các neo vật lý, chúng có thể gây tổn thương màng tế bào của vi sinh vật. Ví dụ, Liu và cộng sự (2013) [81] đã chứng minh rằng cơ chế độc hại của $\mathrm{GO}$ và $\mathrm{GO}$ dạng khử (reduced) liên quan đến sự lắng đọng vật chất trên các tế bào và ứng suất màng do tiếp xúc trực tiếp với các tấm sắc nhọn của vật liệu. Tuy nhiên, cơ chế tiếp xúc trực tiếp nên được xem xét cẩn thận khi nghiên cứu độc tính vì các tác động độc hại vẫn xảy ra ngay cả khi các nano và vi khuẩn không tiếp xúc nhau và tế bào cũng có thể bị chết, ngay cả khi một số loại nano không đính trên bề mặt tế bào.

Một cơ chế về tính kháng vi sinh vật khác liên quan có thể đến sự tương tác của nano với lưu huỳnh và phốt pho của DNA vi khuẩn, dẫn đến việc các tế bào không thể sao chép, do đó giết chết các vi khuẩn [82]. Hạt nano có khả năng khử phốt pho trong dư lượng tyrosine của vi khuẩn Gram âm cũng được xem là một cơ chế tiềm năng của độc tính nano [83]. 


\section{TÍNH CHÂT VÂT LÝ VÀ HÓA HỌC CỦA VLNN Vô CƠ SẼ ẢNH HƯởNG ĐẾN HOẠT ĐộNG KHÁNG KHUẨN CỦA CHÚNG}

Độc tính của hạt nano phụ thuộc vào kích thước, thành phần, các nhóm trên bề mặt và tính chất bên trong của vi khuẩn được thử nghiệm. Các đặc tính của vi khuẩn này bao gồm loại thành tế bào (Gram dương so với Gram âm), tốc độ tăng trưởng và hình thái màng sinh học của vi sinh vật [84]. Tuy nhiên, trong bài tổng quan này, chỉ các tính chất vật lý và hóa học của các VLNN vô cơ đã đề cập ở trên sẽ được được thảo luận tiếp đây.

\subsection{Kích thước của VLNN}

Nhiều nghiên cứu cho rằng độc tính của nano Titanium oxít $\left(\mathrm{TiO}_{2} \mathrm{NP}\right)$ chỉ được thể hiện khi kích thước hạt nano đủ nhỏ [85-90]. Lin và cộng sự (2014) đã nghiên cứu độc tính của năm loại $\mathrm{TiO}_{2} \mathrm{NP}$ với kích thước hạt khác nhau $(10-50 \mathrm{~nm})$ và ở dạng tinh thể trên vi khuẩn $E$. coli. Tác dụng kháng khuẩn của $\mathrm{TiO}_{2} \mathrm{NP}$ giảm khi tăng kích thước hạt và hàm lượng rutile của $\mathrm{TiO}_{2} \mathrm{NP}$. Các $\mathrm{TiO}_{2} \mathrm{NP}$ có cấu trúc tinh thể dạng anatase và kích thước hạt nhỏ hơn sẽ tạo ra hàm lượng ROS nội bào cao hơn và do đó có tác dụng kháng khuẩn lớn hơn [91]. Tương tự như $\mathrm{TiO}_{2} \mathrm{NP}$, nhiều báo cáo đã chỉ ra rằng kích thước hạt có thể ảnh hưởng đến hoạt động kháng khuẩn của ZnO NP [92-94]. Ví dụ, Yamamoto (2001) đã nghiên cứu ảnh hưởng của kích thước hạt của các $\mathrm{ZnO} N \mathrm{NP}$ trong phạm vi $100-800 \mathrm{~nm}$ trên $S$. aureus và $E$. coli. Các nghiên cứu nhận thấy rằng hoạt động kháng khuẩn của $\mathrm{ZnO} \mathrm{NP}$ tăng lên cùng với việc giảm kích thước hạt. Các kết quả khác cũng cho thấy huyền phù $\mathrm{ZnO}$ với các hạt kích thước $12 \mathrm{~nm}$ có hiệu quả hơn huyền phù với kích thước hạt lớn [94]. Lý do có thể là do các ZnO NP có kích thước nhỏ hơn với diện tích bề mặt nhiều hơn đã làm tăng lượng $\mathrm{H}_{2} \mathrm{O}_{2}$ [95].

\subsection{Hình dạng hạt nano}

Các hạt nano $\mathrm{ZnO}$ với kích thước đường kính trung bình $30 \mathrm{~nm}$ cho thấy hoạt tính kháng khuẩn cao nhất. Yamamoto và cộng sự (2004) kết luận rằng hoạt tính kháng khuẩn của bột $\mathrm{ZnO}$ đã tăng lên khi gia tăng giá trị hằng số mạng của ô đơn vị lục giác của $\mathrm{ZnO} \mathrm{NP}$ của bột $\mathrm{ZnO}$. Hằng số mạng của ô đơn vị lục giác của ZnO thông thường là tỉ lệ giữa c/a khoảng 1.6. Đối với các VLNN có carbon trong cấu trúc thì một nghiên cứu có hệ thống đã nghiên cứu tác dụng kháng khuẩn của các huyền phù $\mathrm{GO}$ khác nhau, tùy thuộc vào kích thước khác nhau (khác nhau khoảng100 lần) và sự các phân bố các kích thước đó [96]. Thuộc tính kháng khuẩn của $\mathrm{GO}$ chống lại các tế bào $\mathrm{E}$. coli cao hơn ở các tấm $\mathrm{GO}$ có kích thước lớn so với các tấm $\mathrm{GO}$ có kích thước nhỏ hơn. Lý do có thể là các tấm GO lớn hơn có khả năng bao phủ các tế bào dễ dàng hơn, có thể chặn các vị trí hoạt động của chúng trên màng. Trong khi các tấm GO nhỏ hơn được gắn không hiệu quả vào bề mặt vi khuẩn, dẫn đến hoạt động kháng khuẩn yếu hơn [97].

\subsection{Thuộc tính bề mặt}

Phương pháp nhúng là một trong những phương pháp được sử dụng nhiều nhất trong các phương pháp sửa đổi cấu trúc của VLNN [98-100]. Kết quả chỉ ra rằng các ZnO NP kết hợp cùng bạc có hoạt tính kháng khuẩn tốt hơn so với chỉ một mình $\mathrm{ZnO} N \mathrm{NP}$. Gordon và cộng sự (2011) đã pha tạp oxít sắt lên các hạt ZnO NP để tạo ra các hạt nano từ tính có hoạt tính kháng khuẩn mà sau đó được phát hiện tính kháng khuẩn phụ thuộc vào tỷ lệ trọng lượng giữa $[\mathrm{Zn}]$ : [Fe]. Tỷ lệ này càng cao thì hoạt tính kháng khuẩn càng cao. Hoạt tính kháng khuẩn của hydroxyapatite nanocompozit kết hợp cùng bạc nano đã ức chế đáng kể sự phát triển của E. coli JM110 và Micrococcus luteus [101].

Liu và Kim đã áp dụng nanocompoxít bao gồm chitosan/poly (ethylene glycol/ $\mathrm{ZnO} / \mathrm{Ag}$ làm vật liệu băng vết thương. Kết quả chỉ ra rằng miếng dán hydrogel pha với nano bạc có hoạt tính kháng khuẩn cao hơn hydrogel [102]. Tương tự, các tác giả này đã chứng minh rằng các ống nano $\mathrm{TiO}_{2}$ được kết hợp với bạc nano đã tiêu diệt vi khuẩn $S$. aureus trong vài ngày đầu tiên và ngăn chặn sự bám dính của chúng trong 30 ngày.

\subsection{Kích thước và hình thái của VLNN}

Wang và cộng sự (2007) đã nghiên cứu mối quan hệ giữa hoạt động kháng khuẩn và các định hướng (orientations) khác nhau của mảng $\mathrm{ZnO} \mathrm{NP}$ [103]. Kết quả chỉ ra rằng các mảng nano $\mathrm{ZnO}$ được định hướng ngẫu nhiên cho thấy hoạt động kháng khuẩn tốt hơn chống lại $E$. coli so với các mảng nano ZnO có định hướng lộn xộn hay sắp xếp quá trật tự. 


\section{TİNH HİNH ÚNG DỤNG VLNN TRONG SẢN PHẨM TIÊU DÙNG VÀ THỤ̉C PHẨM Ở VIÊT NAM}

Vào năm 2014 chính phủ Việt Nam đã phê duyệt danh mục 58 công nghệ cao được ưu tiên đầu tư phát triển và danh mục 114 sản phẩm công nghệ cao được khuyến khích phát triển. Trong đó công nghệ vật liệu nano là công nghệ được ưu tiên đầu tư phát triển. Mục tiêu của chính phủ Việt Nam là từ năm 2020-2030 là nâng cao tiềm lực khoa học và công nghệ trong vật liệu và công nghệ nano để có thể giúp Việt Nam nhanh chóng đạt trình độ tiên tiến trong khu vực. Đây là một mục tiêu khá táo bạo và cần nhiều nguồn lực và nhân lực có trình độ có thể thực hiện hóa mục tiêu này.

Về nghiên cứu cơ bản, một số phòng thí nghiệm tại các trường và viện đã bắt đầu tập trung vào nghiên cứu vật liệu và công nghệ nano. Trong số đó, phải kể đến Viện Khoa học vật liệu của Viện Hàn lâm Khoa học và Công nghệ Việt Nam, Viện Công nghệ nano của Đại học Quốc gia TP.HCM, Đại học Khoa học tự nhiên và Đại học Công nghệ của Đại học Quốc gia Hà Nội, Đại học Bách khoa Hà Nội, Viện Nghiên cứu nano của trường Đại học Phenikaa, và Đại học Sư phạm Hà Nội. Bằng cách sử dụng google scholar để thống kê tổng số các bài báo liên quan đến nano và nơi nghiên cứu từ Việt Nam, kết quả cho thấy có trên 15.000 nghiên cứu bao gồm cả kỷ yếu tại các hội nghị từ năm 2015 đến 2020. Nội dung nghiên cứu về ứng dụng trong thực phẩm và tiêu dùng có thể bao gồm các hoạt chất sinh học hay dược liệu [104] [105] màng nano kháng khuẩn bao gói thực phẩm, các chất kháng khuẩn [106] [107, 108], kít thử vi sinh vật trong thực phẩm, màng lọc nước [109-112]. Tổng số đề tài, dự án đã được thực hiện và các sản phẩm công nghệ các doanh nghiệp tự nghiên cứu và phát triển tại Việt Nam từ năm 2010 trở lại đây là khoảng hơn 400 công nghệ, tuy nhiên số lượng các công nghệ được thương mại hóa thành công lại không nhiều [113] .

Hiện nay tại Việt Nam, $\mathrm{y}$ dược và mỹ phẩm là được xem là mảng ứng dụng nhiều nhất của công nghệ nano. Từ ngành dệt (khẩu trang [114], vải dệt [115]), $\mathrm{y}$ dược (sản phẩm thực phẩm chức năng, như nghệ curcumin nano [72, 113,116], cốm cho trẻ em [117]. Tuy nhiên, giống như các nước khác, Việt Nam cũng chưa có qui định cụ thể và chi tiết về các sản phẩm tiêu dùng chứa VLNN [115].

Sản phẩm sử dụng VLNN tại Việt Nam được thống kê qua Bảng 3. Hiện nay, Việt Nam đang tập trung nghiên cứu lĩnh vực nano và đưa sản phẩm nano ra thị trường.

Bảng 3. Các sản phẩm thực phẩm và hàng tiêu dùng có chứa VLNN sản xuất tại Việt Nam

\begin{tabular}{|c|c|c|c|}
\hline Danh mục & VLNN & Nhà cung cấp & Công bố thông tin trên nhãn \\
\hline \multicolumn{4}{|c|}{ Thực phẩm bổ sung } \\
\hline \multirow[t]{5}{*}{ Viên nhộng } & \multirow[t]{5}{*}{ Nghệ nano } & $\begin{array}{l}\text { CurmaGold- Công ty dược } \\
\text { mỹ phẫm CVI }\end{array}$ & $\begin{array}{l}\text { Hạt có kích thước } 50-70 \mathrm{~nm} \text {, tác } \\
\text { dụng trong việc điều trị bệnh dạ dày, } \\
\text { tá tràng, ung thư. }\end{array}$ \\
\hline & & $\begin{array}{l}\text { Nano Curcumin NDN- } \\
\text { Vietlife Cinabet }\end{array}$ & $\begin{array}{l}\text { Hạt nano có độ lớn } \pm 16 \mathrm{~nm} \text {, hỗ trợ } \\
\text { giảm đường huyết, } \mathrm{HbA} 1 \mathrm{c} \text {, và giảm } \\
\text { cholesterol, giảm nguy cơ biến chứng } \\
\text { của bệnh đái tháo đường. }\end{array}$ \\
\hline & & $\begin{array}{l}\text { Scurma Fizzy- Viện Hàn } \\
\text { lâm Khoa học và Công } \\
\text { nghệ Việt Nam }\end{array}$ & $\begin{array}{l}\text { Ức chế đến hơn } 65 \text { chủng vi khuẩn } \\
\text { Hp - Helicobacter pylori là một } \\
\text { trong những nguyên nhân gây nên }\end{array}$ \\
\hline & & $\begin{array}{l}\text { Nano Curcumin-Tam thất- } \\
\text { Xạ đen - Học Viện Quân } \\
\text { Y }\end{array}$ & $\begin{array}{l}\text { các bệnh vê dạ dày } \\
\text { Có tác dụng giảm độc tính sau hóa } \\
\text { trị, xạ trị }\end{array}$ \\
\hline & & $\begin{array}{l}\text { Nano Curcumin } 3 \text { HTD -- } \\
\text { Công ty tinh dầu và chất } \\
\text { thơm- Viện Hàn lâm Khoa }\end{array}$ & $\begin{array}{l}\text { Chứa } 20 \% \text { là nano curcumin có khả } \\
\text { năng hòa tan trong nước, góp phần }\end{array}$ \\
\hline
\end{tabular}




\begin{tabular}{|c|c|c|c|}
\hline & & $\begin{array}{l}\text { học và Công nghệ Việt } \\
\text { Nam }\end{array}$ & $\begin{array}{l}\text { làm tăng khả năng hấp thụ curcumin } \\
\text { vào cơ thể lên đến } 40 \text { lần }\end{array}$ \\
\hline Cốm cho trẻ em & & $\begin{array}{l}\text { Nano Mother Kids -Công } \\
\text { ty dược phầm Phanagreen }\end{array}$ & $\begin{array}{l}\text { Công nghệ nano màng sinh học, giúp } \\
\text { giảm ho ở trẻ nhỏ nhanh chóng }\end{array}$ \\
\hline $\begin{array}{l}\text { Nano Rutin và } \\
\text { Nano Silymarin }\end{array}$ & $\begin{array}{l}\text { Rutin và } \\
\text { Sliymarin }\end{array}$ & $\begin{array}{l}\text { Nano Rutin và Nano } \\
\text { Silymarin - Công ty Cổ } \\
\text { phần Công nghệ mới Nhật } \\
\text { Hải OIC }\end{array}$ & $\begin{array}{l}\text { Hạt nano từ } 20-50 \mathrm{~nm} \text {, giữ được cấu } \\
\text { trúc và tính ổn định trong môi trường } \\
\text { cơ thể }\end{array}$ \\
\hline \multicolumn{4}{|l|}{ Vật dụng y tế } \\
\hline Vải kháng khuẩn & $\mathrm{Ag} N \mathrm{NP}$ & $\begin{array}{l}\text { Sản phẩm của Viện Công } \\
\text { nghệ Môi trường, Viện } \\
\text { Hàn lâm Khoa học và } \\
\text { Công nghệ Việt Nam } \\
\text { Công ty Wakamono }\end{array}$ & $\begin{array}{l}\text { Chống vi khuẩn, vi rút háng khuẩn } \\
\text { vượt trội và lâu dài, tiêu diệt } 99,9 \% \text { vi } \\
\text { khuẩn (E. coli, Bacillus subtilis, } S \text {. } \\
\text { aureus, Salmonella typhi, } \\
\text { Pseudomonas aeruginosal) ngay khi } \\
\text { tiếp xúc }\end{array}$ \\
\hline
\end{tabular}

\section{KẾT LUẬn}

Bài tổng quan này là một bài tổng hợp liên quan đến nhiều nghiên cứu về việc sử dụng các vật liệu nano và công nghệ nano khác nhau trong ngành tiêu dùng và sản xuất thực phẩm. Kết quả nghiên cứu chỉ ra rằng các VLNN vô cơ có thể được sử dụng như một chất ức chế sự phát triển của vi sinh vật có hại, và có khả năng có thể được sử dụng trong các ứng dụng y sinh và an toàn thực phẩm. Trên thế giới, thị trường các mặt hàng có chứa VLNN khá đa dạng và đang có xu hướng tăng lên hàng năm, trải dài trên các lĩnh vực ứng dụng khác nhau. Tuy nhiên, cần nghiên cứu thêm để khẳng định thêm về các ứng dụng tiềm năng của vật liệu nano mới. Tác giả dự đoán rằng cần nhiều nỗ lực hơn nữa để nghiên cứu thêm về độc tính tế bào, về cơ chế làm thế nào mà các tính chất đặc biệt của VLNN (hình dạng, tính chất bề mặt và độ phân tán, v.v.) sẽ ảnh hưởng đến sức khỏe của con người ở cấp độ phân cấp từ tế bào, cơ quan, đến toàn bộ cơ thể.

\section{BẢNG PHỤ LỤC TÊN VIẾT TÁT}

Au: Vàng

Ag: Bạc

G: Graphene

GO: Graphene oxít

NP: Nanoparticle

rGO: reduced graphene oxide

Se: Selenium

\section{TÀI LIỆU THAM KHẢO}

[1] Woodrow Wilson Inventory 2016.

[2] Yip, J., et al., Investigation of antifungal and antibacterial effects of fabric padded with highly stable selenium nanoparticles. J. Appl. Polym. Sci. 131(17)2014.

[3] Kheradmand, E., et al., The antimicrobial effects of selenium nanoparticle-enriched probiotics and their fermented broth against Candida albicans. DARU 22(1), pp. 48, 2014.

[4] Shakibaie, M., et al., Anti-biofilm activity of biogenic selenium nanoparticles and selenium dioxide against clinical isolates of Staphylococcus aureus, Pseudomonas aeruginosa, and Proteus mirabilis. J. Trace Elem. Med. Bio. 29(1), pp. 235-241, 2015.

[5] Chudobova, D., et al., Comparison of the effects of silver phosphate and selenium nanoparticles on Staphylococcus aureus growth reveals potential for selenium particles to prevent infection. FEMS microbiol. lett. 351(2), pp. 195-201, 2014. 
[6] Wang, Q. and T.J. Webster. Selenium Nanoparticles Inhibit Various Bacterial Growth on Paper Towels. in MRS Proceedings. 2014. Cambridge Univ Press.

[7] Mittal, A.K., S. Kumar, and U.C. Banerjee, Quercetin and gallic acid mediated synthesis of bimetallic (silver and selenium) nanoparticles and their antitumor and antimicrobial potential. Journal of colloid and interface science. 431(2), pp. 194-199, 2014.

[8] Tran, P.A. and T.J. Webster, Selenium nanoparticles inhibit Staphylococcus aureus growth. International journal of nanomedicine. 6(2), pp. 1553, 2011.

[9] Namasivayam, S., S. Ganesh, and B. Avimanyu, Evaluation of anti-bacterial activity of silver nanoparticles synthesized from Candida glabrata and Fusarium oxysporum. Int J Med Res. 1(3), pp. 131-136, 2011.

[10] Nam, K.-Y., In vitro antimicrobial effect of the tissue conditioner containing silver nanoparticles. The journal of advanced prosthodontics. 3(1), pp. 20-24, 2011.

[11] Barud, H.S., et al., Antimicrobial bacterial cellulose-silver nanoparticles composite membranes. Journal of Nanomaterials. 2011(2), pp. 10, 2011.

[12] Ansari, M., et al., Evaluation of antibacterial activity of silver nanoparticles against MSSA and MRSA on isolates from skin infections. Biol Med. 3(2), pp. 141-146, 2011.

[13] Lkhagvajav, N., et al., Antimicrobial activity of colloidal silver nanoparticles prepared by sol-gel method. Dig J Nanomater Biostruct. 6(1), pp. 149-154, 2011.

[14] You, J., Y. Zhang, and Z. Hu, Bacteria and bacteriophage inactivation by silver and zinc oxide nanoparticles. Colloids and Surfaces B: Biointerfaces. 85(2), pp. 161-167, 2011.

[15] Jayaseelan, C., et al., Efficacy of plant-mediated synthesized silver nanoparticles against hematophagous parasites. Parasitology research. 111(2), pp. 921-933, 2012.

[16] Kirthi, A.V., et al., Acaricidal, pediculocidal and larvicidal activity of synthesized ZnO nanoparticles using wet chemical route against blood feeding parasites. Parasitology research. 109(2), pp. 461-472, 2011.

[17] Xie, Y., et al., Antibacterial activity and mechanism of action of zinc oxide nanoparticles against Campylobacter jejuni. Applied and environmental microbiology. 77(7), pp. 2325-2331, 2011.

[18] He, L., et al., Antifungal activity of zinc oxide nanoparticles against Botrytis cinerea and Penicillium expansum. Microbiological research. 166(3), pp. 207-215, 2011.

[19] Tayel, A.A., et al., Antibacterial action of zinc oxide nanoparticles against foodborne pathogens. Journal of Food Safety. 31(2), pp. 211-218, 2011.

[20] Premanathan, M., et al., Selective toxicity of $\mathrm{ZnO}$ nanoparticles toward Gram-positive bacteria and cancer cells by apoptosis through lipid peroxidation. Nanomedicine: Nanotechnology, Biology and Medicine. 7(2), pp. 184-192, 2011.

[21] Baek, Y.-W. and Y.-J. An, Microbial toxicity of metal oxide nanoparticles (CuO, NiO, ZnO, and Sb 2 O 3$)$ to Escherichia coli, Bacillus subtilis, and Streptococcus aureus. Science of the Total Environment. 409(8), pp. 1603-1608, 2011.

[22] Seil, J.T. and T.J. Webster, Reduced Staphylococcus aureus proliferation and biofilm formation on zinc oxide nanoparticle PVC composite surfaces. Acta biomaterialia. 7(6), pp. 2579-2584, 2011.

[23] Jayaseelan, C., et al., a. Spectrochimica Acta Part A: Molecular and Biomolecular Spectroscopy. 90(pp. 78-84, 2012.

[24] Akbar, A. and A.K. Anal, Zinc oxide nanoparticles loaded active packaging, a challenge study against Salmonella typhimurium and Staphylococcus aureus in ready-to-eat poultry meat. Food Control. 38(pp. 8895, 2014.

[25] Kasraei, S., et al., Antibacterial properties of composite resins incorporating silver and zinc oxide nanoparticles on Streptococcus mutans and Lactobacillus. Restorative dentistry \& endodontics. 39(2), pp. 109-114, 2014.

[26] Jin, T. and J. Gurtler, Inactivation of Salmonella in liquid egg albumen by antimicrobial bottle coatings infused with allyl isothiocyanate, nisin and zinc oxide nanoparticles. Journal of applied microbiology. 110(3), pp. 704-712, 2011.

[27] Sharma, N., et al., Antibacterial study of silver doped zinc oxide nanoparticles against Staphylococcus aureus and Bacillus subtilis. Drug Invention Today. 5(1), pp. 50-54, 2013.

[28] Sinha, R., et al., Interaction and nanotoxic effect of $\mathrm{ZnO}$ and $\mathrm{Ag}$ nanoparticles on mesophilic and halophilic bacterial cells. Bioresource technology. 102(2), pp. 1516-1520, 2011.

[29] Gunalan, S., R. Sivaraj, and V. Rajendran, Green synthesized ZnO nanoparticles against bacterial and fungal pathogens. Progress in Natural Science: Materials International. 22(6), pp. 693-700, 2012.

[30] Seil, J.T. and T.J. Webster, Antibacterial effect of zinc oxide nanoparticles combined with ultrasound. Nanotechnology. 23(49), pp. 495101, 2012. 
[31] Bala, N., et al., Green synthesis of zinc oxide nanoparticles using Hibiscus subdariffa leaf extract: effect of temperature on synthesis, anti-bacterial activity and anti-diabetic activity. RSC Advances. 5(7), pp. 49935003, 2015.

[32] Yousef, J.M. and E.N. Danial, In vitro antibacterial activity and minimum inhibitory concentration of zinc oxide and nano-particle zinc oxide against pathogenic strains. Journal of Health Sciences. 2(4), pp. 38-42, 2012.

[33] Lipovsky, A., et al., Antifungal activity of $\mathrm{ZnO}$ nanoparticles - the role of ROS mediated cell injury. Nanotechnology. 22(10), pp. 105101, 2011.

[34] Watson, C.Y., et al., Effects of zinc oxide nanoparticles on Kupffer cell phagosomal motility, bacterial clearance, and liver function. International journal of nanomedicine. 10(pp. 4173, 2015.

[35] Schaepe, S.M., Engineering Graphene Oxide Membranes for Contaminant Removal and Bacterial Inactivation. 2015.

[36] Akhavan, O. and E. Ghaderi, Escherichia coli bacteria reduce graphene oxide to bactericidal graphene in a self-limiting manner. Carbon. 50(5), pp. 1853-1860, 2012.

[37] Krishnamoorthy, K., et al., Antibacterial efficiency of graphene nanosheets against pathogenic bacteria via lipid peroxidation. The Journal of Physical Chemistry C. 116(32), pp. 17280-17287, 2012.

[38] Wu, M.-C., et al., Graphene-based photothermal agent for rapid and effective killing of bacteria. ACS nano. 7(2), pp. 1281-1290, 2013.

[39] Some, S., et al., Dual functions of highly potent graphene derivative-poly-L-lysine composites to inhibit bacteria and support human cells. ACS nano. 6(8), pp. 7151-7161, 2012.

[40] Li, R., C. Liu, and J. Ma, Studies on the properties of graphene oxide-reinforced starch biocomposites. Carbohydrate Polymers. 84(1), pp. 631-637, 2011.

[41] Fan, Z., et al., A novel wound dressing based on Ag/graphene polymer hydrogel: effectively kill bacteria and accelerate wound healing. Advanced Functional Materials. 24(25), pp. 3933-3943, 2014.

[42] Pham, V.T., et al., Graphene Induces Formation of Pores That Kill Spherical and Rod-Shaped Bacteria. ACS nano. 9(8), pp. 8458-8467, 2015.

[43] Nellore, B.P.V., et al., Bio-Conjugated CNT-Bridged 3D Porous Graphene Oxide Membrane for Highly Efficient Disinfection of Pathogenic Bacteria and Removal of Toxic Metals from Water. ACS applied materials \& interfaces. 7(34), pp. 19210, 2015.

[44] Nellore, B.P., et al., Antimicrobial peptide-conjugated graphene oxide membrane for efficient removal and effective killing of multiple drug resistant bacteria. RSC advances. 5(24), pp. 18881-18887, 2015.

[45] Chen, J., et al., Graphene oxide exhibits broad-spectrum antimicrobial activity against bacterial phytopathogens and fungal conidia by intertwining and membrane perturbation. Nanoscale. 6(3), pp. 18791889, 2014.

[46] Rago, I., et al. Antimicrobial activity of graphene nanoplatelets against Streptococcus mutans. in Nanotechnology (IEEE-NANO), 2015 IEEE 15th International Conference on. 2015. IEEE.

[47] Zhong, L. and K. Yun, Graphene oxide-modified ZnO particles: synthesis, characterization, and antibacterial properties. International journal of nanomedicine. 10(pp. 79, 2015.

[48] Djurišić, A.B., et al., Toxicity of metal oxide nanoparticles: mechanisms, characterization, and avoiding experimental artefacts. Small. 11(1), pp. 26-44, 2015.

[49] Sharma, V., D. Anderson, and A. Dhawan, Zinc oxide nanoparticles induce oxidative DNA damage and ROS-triggered mitochondria mediated apoptosis in human liver cells (HepG2). Apoptosis. 17(8), pp. 852$870,2012$.

[50] Gurunathan, S., et al., Oxidative stress-mediated antibacterial activity of graphene oxide and reduced graphene oxide in Pseudomonas aeruginosa. Int J Nanomedicine. 7(5901), pp. e14, 2012.

[51] Fu, P.P., et al., Mechanisms of nanotoxicity: generation of reactive oxygen species. Journal of food and drug analysis. 22(1), pp. 64-75, 2014.

[52] Fu, P.P., et al., Phototoxicity and environmental transformation of polycyclic aromatic hydrocarbons (PAHs) - light-induced reactive oxygen species, lipid peroxidation, and DNA damage. Journal of Environmental Science and Health, Part C. 30(1), pp. 1-41, 2012.

[53] Li, Y., et al., Mechanism of photogenerated reactive oxygen species and correlation with the antibacterial properties of engineered metal-oxide nanoparticles. Acs Nano. 6(6), pp. 5164-5173, 2012.

[54] Shi, M., et al., Effects of surface chemistry on the generation of reactive oxygen species by copper nanoparticles. ACS nano. 6(3), pp. 2157-2164, 2012.

[55] Zhang, W., et al., Photogeneration of reactive oxygen species on uncoated silver, gold, nickel, and silicon nanoparticles and their antibacterial effects. Langmuir. 29(15), pp. 4647-4651, 2013. 
[56] Lyon, D.Y., et al., Antibacterial activity of fullerene water suspensions (nC60) is not due to ROS-mediated damage. Nano letters. 8(5), pp. 1539-1543, 2008.

[57] Krishnamoorthy, K., et al., Antibacterial activity of $\mathrm{MgO}$ nanoparticles based on lipid peroxidation by oxygen vacancy. Journal of Nanoparticle Research. 14(9), pp. 1-10, 2012.

[58] Leung, Y.H., et al., Mechanisms of Antibacterial Activity of MgO: Non-ROS Mediated Toxicity of MgO Nanoparticles Towards Escherichia coli. Small. 10(6), pp. 1171-1183, 2014.

[59] Prabhu, S. and E.K. Poulose, Silver nanoparticles: mechanism of antimicrobial action, synthesis, medical applications, and toxicity effects. International Nano Letters. 2(1), pp. 1-10, 2012.

[60] Danilczuk, M., et al., Conduction electron spin resonance of small silver particles. Spectrochimica Acta Part A: Molecular and Biomolecular Spectroscopy. 63(1), pp. 189-191, 2006.

[61] Kim, J.S., et al., Antimicrobial effects of silver nanoparticles. Nanomedicine: Nanotechnology, Biology and Medicine. 3(1), pp. 95-101, 2007.

[62] Seabra, A.B., et al., Nanotoxicity of graphene and graphene oxide. Chemical research in toxicology. 27(2), pp. 159-168, 2014.

[63] Sanchez, V.C., et al., Biological interactions of graphene-family nanomaterials: an interdisciplinary review. Chemical research in toxicology. 25(1), pp. 15-34, 2011.

[64] Liu, Y., et al., Antibacterial activities of zinc oxide nanoparticles against Escherichia coli O157: H7. Journal of Applied Microbiology. 107(4), pp. 1193-1201, 2009.

[65] Sirelkhatim, A., et al., Review on zinc oxide nanoparticles: antibacterial activity and toxicity mechanism. Nano-Micro Letters. 7(3), pp. 219-242, 2015.

[66] Ma, J., et al., Preparation, characterization and antibacterial properties of silver-modified graphene oxide. Journal of Materials Chemistry. 21(10), pp. 3350, 2011.

[67] Sondi, I. and B. Salopek-Sondi, Silver nanoparticles as antimicrobial agent: a case study on E. coli as a model for Gram-negative bacteria. Journal of colloid and interface science. 275(1), pp. 177-182, 2004.

[68] Horie, M., et al., Association of the physical and chemical properties and the cytotoxicity of metal oxide nanoparticles: metal ion release, adsorption ability and specific surface area. Metallomics. 4(4), pp. 350-360, 2012.

[69] Thill, A., et al., Cytotoxicity of $\mathrm{CeO} 2$ nanoparticles for Escherichia coli. Physico-chemical insight of the cytotoxicity mechanism. Environmental science \& technology. 40(19), pp. 6151-6156, 2006.

[70] Eom, H.-J. and J. Choi, Oxidative stress of CeO 2 nanoparticles via p38-Nrf-2 signaling pathway in human bronchial epithelial cell, Beas-2B. Toxicology letters. 187(2), pp. 77-83, 2009.

[71] Park, E.-J., et al., Oxidative stress induced by cerium oxide nanoparticles in cultured BEAS-2B cells. Toxicology. 245(1), pp. 90-100, 2008.

[72] Kim, S., et al., Oxidative stress-dependent toxicity of silver nanoparticles in human hepatoma cells. Toxicology in vitro. 23(6), pp. 1076-1084, 2009.

[73] Neal, A.L., et al., Can the soil bacterium Cupriavidus necator sense ZnO nanomaterials and aqueous Zn2+ differentially? Nanotoxicology. 6(4), pp. 371-380, 2012.

[74] Neal, A.L., What can be inferred from bacterium-nanoparticle interactions about the potential consequences of environmental exposure to nanoparticles? Ecotoxicology. 17(5), pp. 362-371, 2008.

[75] Applerot, G., et al., Understanding the antibacterial mechanism of $\mathrm{CuO}$ nanoparticles: revealing the route of induced oxidative stress. Small. 8(21), pp. 3326-3337, 2012.

[76] Leung, Y., et al., Antibacterial activity of $\mathrm{ZnO}$ nanoparticles with a modified surface under ambient illumination. Nanotechnology. 23(47), pp. 475703, 2012.

[77] Pagnout, C., et al., Role of electrostatic interactions in the toxicity of titanium dioxide nanoparticles toward Escherichia coli. Colloids and Surfaces B: Biointerfaces. 92(pp. 315-321, 2012.

[78] Gogniat, G., et al., The bactericidal effect of $\mathrm{TiO} 2$ photocatalysis involves adsorption onto catalyst and the loss of membrane integrity. FEMS microbiology letters. 258(1), pp. 18-24, 2006.

[79] Zhang, L., et al., Investigation into the antibacterial behaviour of suspensions of $\mathrm{ZnO}$ nanoparticles ( $\mathrm{ZnO}$ nanofluids). Journal of Nanoparticle Research. 9(3), pp. 479-489, 2007.

[80] Akhavan, O. and E. Ghaderi, Toxicity of graphene and graphene oxide nanowalls against bacteria. ACS nano. 4(10), pp. 5731-5736, 2010.

[81] Liu, S., et al., Antibacterial activity of graphite, graphite oxide, graphene oxide, and reduced graphene oxide: membrane and oxidative stress. ACS nano. 5(9), pp. 6971-6980, 2011.

[82] Hatchett, D.W. and H.S. White, Electrochemistry of sulfur adlayers on the low-index faces of silver. The Journal of Physical Chemistry. 100(23), pp. 9854-9859, 1996. 
[83] Kokubo, H., et al., Multi-core cable-like TiO2 nanofibrous membranes for dye-sensitized solar cells. Nanotechnology. 18(16), pp. 165604, 2007.

[84] Hajipour, M.J., et al., Antibacterial properties of nanoparticles. Trends in biotechnology. 30(10), pp. 499511, 2012.

[85] Jiang, J., G. Oberdörster, and P. Biswas, Characterization of size, surface charge, and agglomeration state of nanoparticle dispersions for toxicological studies. Journal of Nanoparticle Research. 11(1), pp. 77-89, 2009.

[86] Kim, D.S. and S.-Y. Kwak, Photocatalytic inactivation of E. coli with a mesoporous TiO2 coated film using the film adhesion method. Environmental science \& technology. 43(1), pp. 148-151, 2008.

[87] Kiser, M., et al., Titanium nanomaterial removal and release from wastewater treatment plants. Environmental science \& technology. 43(17), pp. 6757-6763, 2009.

[88] Park, S., et al., Toxic effects of titanium dioxide nanoparticles on microbial activity and metabolic flux. Biotechnology and bioprocess engineering. 17(2), pp. 276-282, 2012.

[89] Tong, T., et al., Cytotoxicity of commercial nano-TiO 2 to Escherichia coli assessed by high-throughput screening: effects of environmental factors. Water research. 47(7), pp. 2352-2362, 2013.

[90] Xiong, S., et al., Size of $\mathrm{TiO} 2$ nanoparticles influences their phototoxicity: an in vitro investigation. Archives of toxicology. 87(1), pp. 99-109, 2013.

[91] Lin, X., et al., Toxicity of TiO 2 nanoparticles to Escherichia coli: effects of particle size, crystal phase and water chemistry. PloS one. 9(10), pp. e110247, 2014.

[92] Yamamoto, O., Influence of particle size on the antibacterial activity of zinc oxide. International Journal of Inorganic Materials. 3(7), pp. 643-646, 2001.

[93] Jones, N., et al., Antibacterial activity of $\mathrm{ZnO}$ nanoparticle suspensions on a broad spectrum of microorganisms. FEMS microbiology letters. 279(1), pp. 71-76, 2008.

[94] Padmavathy, N. and R. Vijayaraghavan, A comparative study on antibacterial properties of $\mathrm{MgO}$ nanoparticles prepared under different calcination temperature. Enhanced Science and Technology of Advanced Material. 8(1)2008.

[95] Ohira, T., et al., Antibacterial activity of $\mathrm{ZnO}$ powder with crystallographic orientation. Journal of Materials Science: Materials in Medicine. 19(3), pp. 1407-1412, 2008.

[96] Liu, J., J. Tang, and J.J. Gooding, Strategies for chemical modification of graphene and applications of chemically modified graphene. Journal of Materials Chemistry. 22(25), pp. 12435-12452, 2012.

[97] Liu, S., et al., Lateral dimension-dependent antibacterial activity of graphene oxide sheets. Langmuir. 28(33), pp. 12364-12372, 2012.

[98] Yamamoto, N., et al., Inhibitory mechanism by polysialic acid for lamina-specific branch formation of thalamocortical axons. The Journal of Neuroscience. 20(24), pp. 9145-9151, 2000.

[99] Lin, Y.-S. and C.L. Haynes, Synthesis and characterization of biocompatible and size-tunable multifunctional porous silica nanoparticles. Chemistry of Materials. 21(17), pp. 3979-3986, 2009.

[100] Manna, P., et al., Contribution of nano-copper particles to in vivo liver dysfunction and cellular damage: Role of I $\kappa \mathrm{B} \alpha / \mathrm{NF}-\kappa \mathrm{B}, \mathrm{MAPKs}$ and mitochondrial signal. Nanotoxicology. 6(1), pp. 1-21, 2012.

[101] Miranda, M., et al., Ceramic/metal biocidal nanocomposites for bone-related applications. Journal of Materials Science: Materials in Medicine. 23(7), pp. 1655-1662, 2012.

[102] Liu, Y. and H.-I. Kim, Characterization and antibacterial properties of genipin-crosslinked chitosan/poly (ethylene glycol)/ZnO/Ag nanocomposites. Carbohydrate polymers. 89(1), pp. 111-116, 2012.

[103] Wang, X., et al., A study on the antibacterial activity of one-dimensional ZnO nanowire arrays: effects of the orientation and plane surface. Chemical Communications42), pp. 4419-4421, 2007.

[104] Nguyen, D.T., et al., Dual interactions of amphiphilic gelatin copolymer and nanocurcumin improving the delivery efficiency of the nanogels. Polymers. 11(5), pp. 814, 2019.

[105] Nguyen, N.N.T., et al., Synergic activity against MCF-7 breast cancer cell growth of nanocurcuminencapsulated and cisplatin-complexed nanogels. Molecules. 23(12), pp. 3347, 2018.

[106] Vo, Q.V. and Q.C. Le, Chế tạo giấy kháng khuẩn từ nano Bạc và giấy Dó truyền thống của Việt Nam. 2019.

[107] Bao, V.-V.Q., L.D. Vuong, and L.V. Luan, Biomimetic synthesis of silver nanoparticles for preparing preservative solutions for mandarins (Citrus Deliciosa Tenore). Nano LIFE. 8(01), pp. 1850003, 2018.

[108] Ngo, T.M.P., et al., Characteristics and Antimicrobial Properties of Active Edible Films Based on Pectin and Nanochitosan. International Journal of Molecular Sciences. 21(6), pp. 2224, 2020.

[109] Duong, H.T., et al., Occurrence of perfluoroalkyl acids in environmental waters in Vietnam. Chemosphere. 122(1), pp. 115-124, 2015. 
[110] Nguyen, T.H., et al., Laterite as a low-cost adsorbent in a sustainable decentralized filtration system to remove arsenic from groundwater in Vietnam. Science of The Total Environment. 699(pp. 134267, 2020.

[111] Nu, D.T.T., et al., Preparation and characterization of nano $\delta$-MnO2-blended cellulose acetate membrane. Vietnam Journal of Chemistry. 57(6), pp. 741-746, 2019.

[112] Tran, H., et al., Pilot Study of Brackish Water Treatment using Dual Stage Nanofi ltration for Domestic Use in Thu Bon Basin, Vietnam. Journal of Membrane Science and Research. 4(2), pp. 69-73, 2018.

[113] Bộ Khoa học và Công nghệ, Một số kết quả hỗ trợ thương mại hóa kết quả nghiên cứu công nghệ nano. 2018.

[114] Nam, W.V., Vải kháng khuẩn nano thiên nhiên của người Việt. Thanhnien2020.

[115] Đại học Khoa học Tự nhiên TP. HCM, Nghiên cứu ứng dụng nhiều vật liệu Nano tiên tiến trong phát triển xanh. 2020.

[116] Bộ Khoa học và Công nghệ- Cục thông tin Khoa học và Công nghệ Quốc Gia, Nghiên cứu ứng dụng công nghệ nano trong trồng điều. 2019.

[117] Green, P.A., Sản phẩm trị ho đầu tiên ứng dụng công nghệ nano tại Việt Nam. 2019.

Ngày nhận bài: 01/04/2020

Ngày chấp nhận đăng:19/08/2020 